\title{
ADOPTION OF SHORT MESSAGE SERVICE: GENDER DIFFERENCE
}

\author{
ChongWoo Park, Georgia Gwinnett College, cpark@ggc.edu \\ Dong-gook Kim, Dalton State College,dkim@daltonstate.edu \\ Chulsung Kim, Georgia GwinnettCollege, ckim@ggc.edu
}

\begin{abstract}
While the adoption of mobile devices has recently received research attention, there has been little research focusing on a specific application or service running in mobile devices. In this study, we examine the adoption of short message service (SMS) with the technology acceptance model. The model has been assessed with the data collected from 225 SMS users. Results from the partial least squares analysis show that perceived ease of use of SMS positively affects perceived usefulness of SMS and intention to adopt SMS, and perceived usefulness of SMS also positively affects intention to adopt SMS. Comparing the two factors, perceived usefulness is more influential than perceived ease of use in the SMS adoption, which implies that extrinsic, i.e., task-oriented, characteristics of SMS may be more important than its intrinsic characteristics in the adoption decision. This study includes how the gender moderates the effects of the two factors on the SMS adoption, showing that the effect of perceived ease of use on the SMS adoption is stronger for female. Implications and future research are discussed.
\end{abstract}

Keywords: Short Message Service (SMS), Texting, M-learning, IT Adoption, Gender Difference

\section{INTRODUCTION}

Since the advent of mobile technology, its use for learning has received research attention with the name of $\mathrm{m}$ learning in practice and academia. According to an m-learning market research report [1], the revenue of m-learning market in the U.S. reached $\$ 632.2$ million in 2009 and will reach up to $\$ 1.4$ billion by 2014 . With the development and innovation of mobile technology, various mobile services have been introduced.

One of the most popular mobile devices is a cell phone, which has provided various services from a simple phone call service to short message service (SMS), and to Internet access service and global positioning systems service. Prior research in m-learning has discussed the use of such mobile services for learning - access to the learning contents on the Web, SMS for interactive learning communications, and so on.

Benefits of using SMS for learning include high availability, platform independence, and cost. First, most college students carry cell phones. Second, SMS is a basic service that any kind of cell phones, from a basic phone to a smartphone, can provide. Third, most cell phone users have SMS or can add it easily without incurring a significant cost. In summary, SMS has a good potential as an m-learning tool in and out of the classroom. While the availability of technology is important, it does not mean that people will adopt the technology for learning. It seems that SMS is available to many college students, but their adoption of SMS for learning has little been discussed in the m-learning literature.

While SMS has many good features for m-learning, it has been mainly used for personal communication. If such a personal communication tool is forced to be used as an academic tool, there may be some resistance from students. Further, instructors and institutions may be unable to force students to use their personal devices (e.g., cell phones) as a learning tool. Therefore, in order to promote students' voluntary participation, we need to understand what can motivate students to adopt SMS for m-learning.

This study employs the technology acceptance model (TAM) to examine students' intention to adopt SMS for learning at college. TAM has been a widely used model in studying the adoption of information systems and/or information technology, and validated in various contexts including m-learning [2]. By using the TAM, we can evaluate college students' willingness to adopt SMS for learning. In addition, we can better understand the effectiveness of the two factors - usefulness and ease of use - leading to the adoption and their interrelationship in the research model.

\section{e-Learning and $m$-Learning}

\section{LITERATURE REVIEW}

The term "e-learning" refers to learning through the Internet [3]. Therefore, personal desktop or laptop computers with the Internet access are required for e-learning. Typical e-learning tools include course management system (e.g., Blackboard), video conferencing, email, chat-room, and Weblog [4]. A main benefit of e-learning is 


\section{Issues in Information Systems}

Volume 14, Issue 1, pp.10-20, 2013

geographic independence. That is, instructors and students can interact in real-time (synchronous) or in non-real time (asynchronous) even when they are in different locations [5]. Geographic freedom achieved through e-learning can be enhanced further if hardware involved is more portable.

Mobile learning (m-learning) is a new branch of e-learning, which uses mobile devices that can access the Internet wirelessly-e.g., cell phone, smartphone, tablet devices-as learning and teaching tools [6]. Especially technological advance of smartphones and tablet devices allows easy access to the aforementioned traditional elearning tools over the cellular and Wi-Fi network. The upshot is that students and instructors can access various elearning tools using their mobile devices at almost anywhere. As a result, m-learning enhances geographic freedom further by allowing students to have individualized learning experience anywhere at any time. For example, students and instructors can utilize their spare time while traveling in a train or bus to finish their homework or lesson preparation [7].

Benefits of m-learning in empirical studies are plenty, such as enhancing availability and accessibility of information networks [8,9], engaging students in learning-related activities in diverse physical locations, supporting group work on projects, and enhancing communication and collaborative learning in the classroom [8].

\section{SMS as an m-Learning Tool}

While the smartphone and tablet device adoption rate among college students is rising, a large portion of students still carries non-smartphones. According to Anderson [10], non-smartphones account for $51 \%$ of mobile communication devices on college campuses, meaning that many students still cannot access traditional e-learning tools through their mobile device because most e-learning tools require the Internet access and/or an application download. On the other hand, SMS, or commonly known as text messaging, is supported by nearly every mobile phone including both smartphones and non-smartphones. SMS is a communication method for exchanging short texts, typically less than 160 characters, predominantly between mobile phones. For some service carriers, a message longer than 160 characters is automatically divided and sent as multiple messages.

We compare SMS with other traditional e-learning tools in terms of important functional evaluation criteria for online communication such as flexibility, distribution speed, information richness, availability, topic orientation, and degree of interaction, which have been suggested by Shim and Guo [4]. As shown in Table 1, while SMS and instant message are very similar in most criteria, SMS is superior to the latter in terms of availability. Text message can be delivered to students virtually wherever they are as long as they have a cell phone. Thus, SMS aligns itself very well, if not best, with the main goal of m-learning - learning anywhere at any time. In addition, SMS has a higher adoption rate (especially among young people), faster distribution speed, and higher degree of interaction over other e-learning tools. Some weaknesses of SMS include low flexibility and low information richness as its message size is limited to 160 text characters.

Table 1. Comparison of SMS and traditional e-learning tools

\begin{tabular}{lllllll}
\hline & Flexibility & $\begin{array}{l}\text { Distribution } \\
\text { Speed }\end{array}$ & $\begin{array}{l}\text { Information } \\
\text { Richness }\end{array}$ & Availability & $\begin{array}{l}\text { Topic } \\
\text { Orientation }\end{array}$ & $\begin{array}{l}\text { Degree of } \\
\text { Interaction }\end{array}$ \\
\hline Weblog & High & Moderate & High & High & Strong & High \\
E-mail & High & Moderate & Moderate & High & Weak & Moderate \\
BBS & Low & Moderate & High & High & Weak & High \\
Homepage & Very low & Slow & High & High & Strong & Low \\
$\begin{array}{l}\text { Instant } \\
\text { message }\end{array}$ & Moderate & Real-time & Low & Moderate & Weak & High \\
SMS & Low & Real-time & Low & High & Weak & High \\
\hline
\end{tabular}

SMS is immensely popular nowadays. According to Purcell, Entner, and Henderson [11], 82\% of U.S. adults use cell phones, and $72 \%$ of them use SMS. Such popularity is even greater among young people. According to a 2009 national survey [12], teenagers use their cell phone for SMS more frequently than for phone calls - sending or receiving an average of 2,899 text messages a month compared to making or receiving only 191 cell phone calls. Such trend seems to be carried over to young college students. When such high popularity and wide availability of SMS are considered, SMS lends itself to be a potentially great m-learning tool. 


\section{Issues in Information Systems}

Volume 14, Issue 1, pp.10-20, 2013

\section{The Use of SMS in Higher Education}

Previous studies show that the use of SMS makes positive effects on learning. In general, SMS can be used as a oneor two-way communication method in higher education. A typical use of one-way SMS includes alerts and reminders, such as notification of timetable changes and library loans. For example, Naismith [13] used SMS to deliver administrative messages to students, and students felt that SMS was useful and that it complemented email well. Another example of one-way SMS can be found in Cavus and Ibrahim's study [14], in which SMS delivered some learning content- new technical English words - to students so that they could learn the technical words anywhere at any time. Its results show that students enjoyed learning new words with the help of their mobile phones. To test the effectiveness of SMS, Rau, Gao, and $\mathrm{Wu}$ [15] sent learning materials (e.g., exercise, notes) after regular lecture and reminding text messages (with some encouraging messages) of upcoming quiz. They found some positive effects of SMS such as reduced pressure and increased motivation.

Stone, Briggs, and Smith [16] tested SMS for two-way communications to complete non-graded exercises as well as graded works. The results show that students liked using SMS and were very responsive to the mobile devices for interaction and learning and that they liked SMS more than any other message applications including email. This was because students felt that the data they received and sent through SMS was more personal [16]. In addition, Garner, Francis, and Wales [17] found that students recognized SMS to be immediate, convenient, and personal. They suggest that instructors and students can interact in real time through SMS, and thus instructors can influence students' action and understanding of situations. Some researchers [18] even used SMS in a classroom to supplement a regular lecture — similar to a clicker system but a lot more social.

\section{Factors Affecting m-Learning Adoption}

Much research has been done to identify the benefits of m-learning and the use of SMS in m-learning. On the other hand, the factors affecting SMS adoption in m-learning have been scarcely researched. In the computer-mediated communication literature, Zagorsky [19] pointed out that the factors affecting students' acceptance of the computermediated communication tools such as email and instant messaging should be studied. Bures, Abrami, and Amundsen [20] studied why some university students are more motivated to learn via computer conferencing. The research found that those students who believed that computer conferencing would help them learn the course materials (outcome-expectation) and they could acquire the ability to use computer conferencing (self-efficacy) were more likely to be active online.

Liu, Li, and Carlsson [2] focused on the adoption of m-learning products that are specifically designed for $\mathrm{m}$ learning (i.e., dedicated m-learning tools). Using the TAM, they studied the factors driving the adoption of such $\mathrm{m}$ learning tools. Their study found that perceived near- and long-term usefulness and personal innovativeness are three significant motivators of m-learning acceptance.

In this paper, we focus on the use of SMS in m-learning, which is not a dedicated m-learning tool. Through the lens of TAM, we study what factors can promote students' adoption of SMS as an m-learning tool.

\section{HYPOTHESES}

Information systems (IS) research has long studied how to properly measure IT adoption and success. Several IS models have received substantial research attention in association with measuring IT adoption and success. For example, the task technology fit model focuses on user evaluations of IS/IT by using fit between task and system characteristics [21]; the IS success model has focused on system use and user satisfaction based on system quality and information quality [22]. While such models contribute to the IT adoption and IS success literature, one of the most widely used models predicting IT adoption is the technology acceptance model (TAM), which focuses on individual acceptance of technology based on usefulness and ease of use [23]. In this study, we have employed the TAM to understand students' adoption of SMS for learning.

According to the TAM literature, IT adoption is influenced by two individual perceptions: usefulness, which is defined as "the degree to which a person believes that using a particular system would enhance his or her job performance," and ease of use, which refers to "the degree to which a person believes that using a particular system would be free of effort" [23, p. 320]. Many IT adoption studies have shown that perceived usefulness (PU) and perceived ease of use (PEOU) affect intended adoption of IT. Both PU and PEOU are of user assessments of IT characteristics, but they involve different aspects of IT characteristics. While PU assesses the task-oriented characteristics of IT, PEOU is related to the assessment of intrinsic characteristics of IT such as its interface. In 


\section{Issues in Information Systems}

Volume 14, Issue 1, pp.10-20, 2013

addition to the two perceptions' direct effects on the intention to adopt, the original TAM studies also suggest that PU mediates the effect of PEOU on the intention to adopt, i.e., the direct effect from PEOU to PU [23].

In this study, we employ the TAM to examine students' intention to adopt SMS for learning. The relationships among the three main constructs of TAM will be tested by investigating the following three hypotheses.

H1: Perceived usefulness of SMS will affect a student's intention to adopt the SMS for learning.

H2: Perceived ease of use of SMS will affect a student's intention to adopt the SMS for learning.

H3: Perceived ease of use of SMS will affect perceived usefulness.

Gender has received research attention as a factor influencing IT adoption. Gefen and Straub [24] extended the TAM by hypothesizing and testing the effects of gender on the perception and on the adoption of e-mail service. Their results show that women rate the perceived usefulness and the perceived ease of use of email higher than men do, and women's adoption of e-mail is greater than that of men. This implies that there is gender difference in the perception and in the adoption of communication technology such as an e-mail service.

Venkatesh and his colleagues [25] formulated the unified theory of acceptance and use of technology and tested gender as a moderator in the TAM. They found that the effect of perceived usefulness on intention to adopt is moderated by gender and the effect is greater for men, and that the effect of perceived ease of use on intention to adopt is moderated by gender and the effect is greater for women. These different moderating effects can be explained by research on gender differences. According to studies on gender, men tend to be more task-oriented [26] and performance expectancies are more likely to be salient to men [25]. Thus, the influence of performance expectancy such as perceived usefulness will be stronger for men. On the other hand, Venkatesh and Morris [27] define effort expectancy as the degree of ease associated with the use of IT system, and suggest from the literature review that effort expectancy is more salient for women. Thus, the ease of use construct related to effort expectancy will be a stronger determinant of individual's intention for women [25].

Building upon the extended TAM literature, we include and test gender as a moderator in the adoption of SMS for learning. Thus, we state the following hypotheses.

H4: The effect of perceived usefulness on intention to adopt SMS for learning will be greater for male.

H5: The effect of perceived ease of use on intention to adopt SMS for learning will be greater for female.

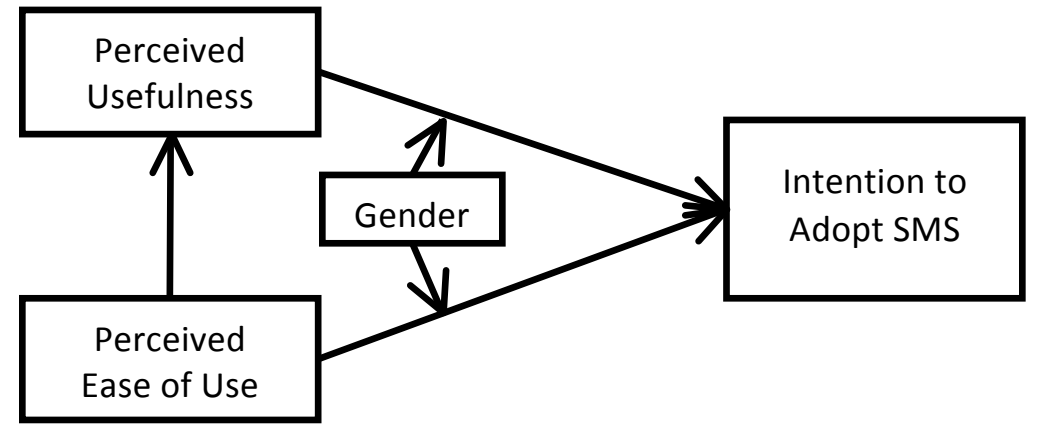

Figure 1. Research Model

\section{Participants}

\section{RESEARCH METHODS}

A structured survey was conducted to test the causal relationships between constructs in the research model of SMS adoption for learning. College students taking an introductory chemistry course participated in the survey. Some simple quizzes regarding the introductory chemistry course were sent to those students via SMS and they were asked to answer via SMS a couple of weeks before they took the survey. Simple quizzes include a short answer question of "Why do successive ionization energies of a given element always increase?" and a multiple choice question of "If a slow step precedes a fast step in a two-step mechanism, do the substances in the fast step appear in the rate law? a) Yes, b) No, c) Need additional information." This exercise of using SMS for class quizzes would help participants understand how SMS can be used for learning and better appreciate the context of SMS use for learning.

Two hundred twenty nine college students from a southeastern state college in the United States were recruited for this survey. Four students were dropped from the response pool because they failed to complete the questionnaire. 


\section{Issues in Information Systems}

Volume 14, Issue 1, pp.10-20, 2013

The demographic information is presented in Table 2, which shows that most participants are currently users of SMS and are eligible to answer the questions on SMS adoption.

Table 2. Demographic Information of Participants

\begin{tabular}{lcc}
\hline Demographic profile & Frequency & Percent (\%) \\
\hline Gender & 85 & \\
Male & 140 & 37.8 \\
Female & 225 & 62.2 \\
Total & & 100.0 \\
Age & 1 & \\
$<18$ & 147 & 0.5 \\
$18-20$ & 34 & 65.3 \\
$21-22$ & 13 & 15.1 \\
$23-25$ & 30 & 5.8 \\
$25<$ & 225 & 13.3 \\
Total & & 100.0 \\
Current subscription to short message service & 209 & \\
Yes & 16 & 92.9 \\
No & 225 & 7.1 \\
Total & & 100.0 \\
Length of time using short message service & 14 & \\
Less than 6 months & 15 & 6.2 \\
6 months to 1 year & 28 & 6.7 \\
1 years to 2 years & 44 & 12.4 \\
2 years to 3 years & 124 & 19.6 \\
More than 3 years & 225 & 55.1 \\
Total & & 100.0 \\
\hline
\end{tabular}

\section{Survey Instrument}

Participants were first asked to provide demographic information such as age, major, gender, ownership of cell phone and SMS, years of SMS use, and frequency of SMS use. The survey instrument to test the research model was adapted from the original TAM scales proposed by Davis [23]. Most were rewritten to reflect SMS for learning of this study. The perceived usefulness of SMS was measured with five items, the perceived ease of use of SMS was with four items, and the intention to adopt SMS for learning was with four items. The final survey consists of 10 demographic questions and 135 -point Likert scale items $(1=$ strongly disagree, $2=$ disagree, $3=$ neutral, $4=$ agree, $5=$ strongly agree). The specific constructs and measures in the survey questionnaire are available upon request.

\section{ANALYSIS AND RESULTS}

Partial Least Squares (PLS) analysis was used as the primary analysis tool in this study [28]. PLS is an extension of the multiple linear regression model. It is also referred to as path analysis with composites, or soft modeling [29]. PLS is an advanced statistical method that is based on the linear transformation from a large number of descriptors to a smaller number of latent variables. PLS computes optimal linear relationships between latent variables in an attempt to account for as much of the manifest factor variation as possible [30]. It first estimates loadings of indicators on constructs, i.e., measurement model, and then iteratively estimates causal relationships among constructs, i.e., structural model [31]. The three paths in the TAM part of the research model are analyzed simultaneously in one PLS analysis.

\section{Measurement Model}

With the measurement model, we evaluate construct validity and reliability by examining the psychometric properties of the measures. Convergent validity is assessed through standardized loadings for each factor model. For 


\section{Issues in Information Systems}

Volume 14, Issue 1, pp.10-20, 2013

convergent validity, the shared variance between each item and its associated construct should exceed the error variance. This translates into a standardized loading of 0.707 or higher. Table 3 shows the standardized loadings, which are all larger than the 0.707 threshold.

Three measures were used to assess internal consistency of each construct: Cronbach's alpha, composite reliability, and average variance extracted (AVE). The Cronbach's alpha and composite reliability value are generally expected to be 0.7 or higher, indicating extensive evidence of reliability. Values of 0.80 or higher indicate exemplary evidence [32,33]. At the same time, a score between 0.60 and 0.70 may also be acceptable for exploratory research $[34,35]$. Table 3 shows the Cronbach's alpha, composite reliability, and AVE values for each construct. All three constructs have an alpha value of 0.9 or higher. Composite reliability values for all three constructs are 0.9 or higher, indicating exemplary composite reliability.

The third measure of construct reliability is the AVE, which compares the amount of variance obtained from indicators with variance due to measurement error [36, 37]. Acceptable levels for the AVE are 0.5 or higher [36]. As shown in Table 3, all constructs meet this criterion. Taken together, the three measures indicate that the constructs are very reliable.

Table 3. Construct Analysis

\begin{tabular}{llllll}
\hline Construct & Item & $\begin{array}{l}\text { Standardized } \\
\text { Loading }\end{array}$ & $\begin{array}{l}\text { Cronbach's } \\
\text { Alpha }\end{array}$ & $\begin{array}{l}\text { Composite } \\
\text { Reliability }\end{array}$ & AVE \\
\hline Usefulness & USEFUL1 & $\mathbf{0 . 8 8 8}$ & $\mathbf{0 . 9 5 4}$ & $\mathbf{0 . 9 6 5}$ & $\mathbf{0 . 8 4 5}$ \\
& USEFUL2 & $\mathbf{0 . 9 3 2}$ & & & \\
& USEFUL3 & $\mathbf{0 . 9 2 2}$ & & & \\
& USEFUL4 & $\mathbf{0 . 9 3 1}$ & & & \\
Ease of Use & USEFUL5 & $\mathbf{0 . 9 2 2}$ & & $\mathbf{0 . 9 6 3}$ & \\
& EOU1 & $\mathbf{0 . 9 2 1}$ & $\mathbf{0 . 9 4 9}$ & & \\
& EOU2 & $\mathbf{0 . 9 5 3}$ & & & \\
EOU3 & $\mathbf{0 . 9 2 6}$ & & & \\
& EOU4 & $\mathbf{0 . 9 2 4}$ & & $\mathbf{0 . 9 6 0}$ & \\
& Intention to Adopt & $\mathbf{0 . 8 8 6}$ & $\mathbf{0 . 9 4 4}$ & & \\
& IA2 & $\mathbf{0 . 9 4 6}$ & & & \\
& IA3 & $\mathbf{0 . 9 3 9}$ & & & \\
& IA4 & $\mathbf{0 . 9 3 2}$ & & & \\
\hline
\end{tabular}

In order to evaluate discriminant validity, we calculated each indicator's loading on its own construct and its crossloadings on all other constructs. As shown in Table 4, each indicator has a higher loading with its intended construct than its cross-loadings with any other constructs. For example, USEFUL1 loads higher on Usefulness $(0.888)$ than on Ease of Use (0.559) or on Intention to Adopt (0.654). In addition, all indicators for their intended construct form a block with similar loadings when the loadings are examined across the rows in each column. A block of the indicators for their intended construct shows higher loadings collectively than the loadings of other blocks. From these results, discriminant validity is established.

Table 4. Construct Loadings and Cross Loadings

\begin{tabular}{lllll}
\hline Construct & Item & 1 & 2 & 3 \\
\hline 1. Usefulness (USEFUL) & USEFUL1 & $\mathbf{0 . 8 8 8}$ & 0.559 & 0.654 \\
& USEFUL2 & $\mathbf{0 . 9 3 2}$ & 0.505 & 0.645 \\
& USEFUL3 & $\mathbf{0 . 9 2 2}$ & 0.486 & 0.690 \\
& USEFUL4 & $\mathbf{0 . 9 3 1}$ & 0.554 & 0.720 \\
& USEFUL5 & $\mathbf{0 . 9 2 2}$ & 0.563 & 0.692 \\
2. Ease of Use (EOU) & EOU1 & 0.522 & $\mathbf{0 . 9 2 1}$ & 0.509 \\
& EOU2 & 0.551 & $\mathbf{0 . 9 5 3}$ & 0.531 \\
& EOU3 & 0.549 & $\mathbf{0 . 9 2 6}$ & 0.579
\end{tabular}




\section{Issues in Information Systems}

Volume 14, Issue 1, pp.10-20, 2013

\begin{tabular}{lllll} 
& EOU4 & 0.541 & $\mathbf{0 . 9 2 4}$ & 0.551 \\
3. Intention to Adopt (IA) & IA1 & 0.691 & 0.633 & $\mathbf{0 . 8 8 6}$ \\
& IA2 & 0.687 & 0.561 & $\mathbf{0 . 9 4 6}$ \\
& IA3 & 0.670 & 0.476 & $\mathbf{0 . 9 3 9}$ \\
& IA4 & 0.692 & 0.482 & $\mathbf{0 . 9 3 2}$ \\
\hline
\end{tabular}

\section{Hypothesis Testing}

Table 5 and Fig. 2 show the results of hypothesis testing in our study. While the relationships between constructs are measured through the path coefficients and their significance levels, i.e., t-values, the explanatory power of the model is expressed as $\mathrm{R}^{2}$ values. We computed the path coefficients with the entire sample size of 225 , and employed the bootstrapping method with 500 re-samples to determine the t-value for each relationship. A t-value of 2.58 or higher indicates a significance level of 0.01 . All three relationships were positive and significant at the 0.01 level. Thus, $\mathrm{H} 1, \mathrm{H} 2$, and $\mathrm{H} 2$ were supported.

The variance in the two dependent constructs- $\mathrm{PU}$ and Intention to Adopt - was explained to varying degrees by the model. According to R2 of 0.58 , the two independent constructs, PU and PEOU, explain $58 \%$ of the variance of the dependent construct, Intention to Adopt. Similarly, PEOU explains 34\% of the variance of PU.

The moderating effect of gender was tested with the statistical procedure used by Keil et al. [38]. Results in Table 5 show that the path coefficient from perceived usefulness to intention to adopt for male was not significantly greater than the corresponding path coefficient for female. Therefore, $\mathrm{H} 4$ was not supported. The path coefficient from perceived ease of use to intention to adopt for female was significantly greater than the corresponding path coefficient for male. Therefore, H5 was supported.

Table 5. Gender Differences in the Salience of PU and PEOU in Determining Intention to Adopt

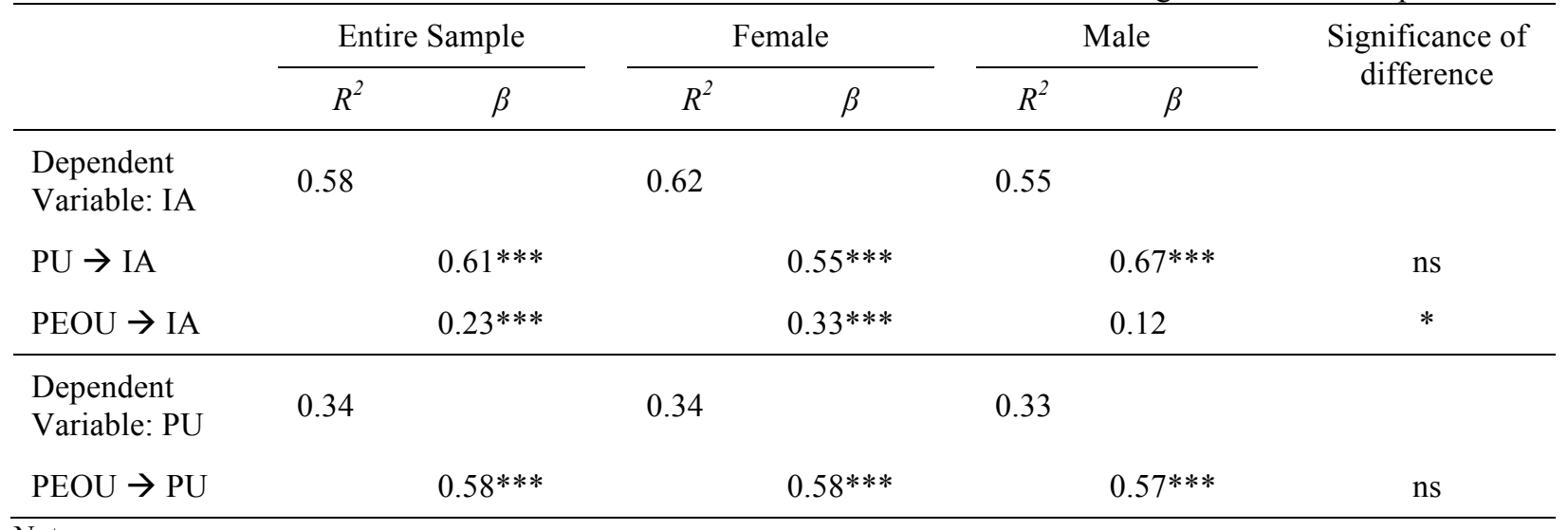

Notes:

1. The difference column presents the significance of difference in path coefficients between the subsamples of female and male. Specifically, the significance of difference was calculated using the procedure described in Keil et al. [38, p. 315].

2. ns: non-significant; $* \mathrm{p}<0.05 ; * * \mathrm{p}<0.01 ; * * * \mathrm{p}<0.001$ 


\section{Issues in Information Systems}

Volume 14, Issue 1, pp.10-20, 2013

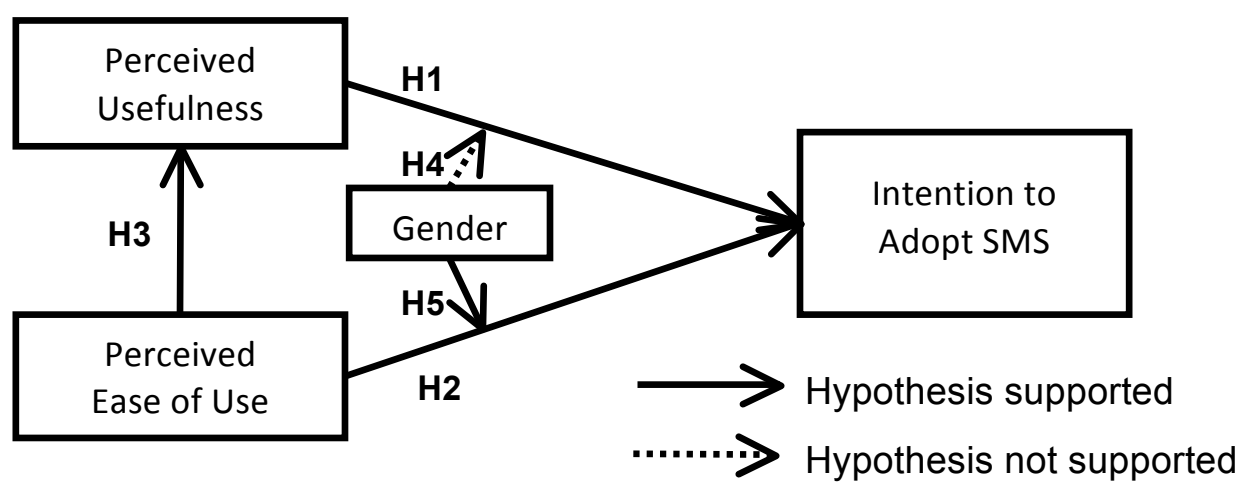

Figure 2. Hypothesis Testing Results

\section{DISCUSSION AND IMPLICATIONS}

SMS is a very popular service for cell phone users. A survey shows that SMS is one of the main means for social communication among many young people including college-aged adults [12]. SMS has a good potential as a learning tool in higher education, but there are some limitations since it has been mainly used for personal communication. Use of SMS for learning requires students to reveal their cell phone numbers, but instructors may not be able to force students to do so. Once students decide to participate in learning through SMS, they may not be able to easily turn off the messages sent by instructors. This may evoke some resistance from students against adopting SMS for learning.

In order to overcome the limitations and promote the use of SMS for learning, we should better understand how and why students use and accept SMS for learning. In this section, we discuss important implications for both research and practice from our findings and suggest some directions for future research.

\section{Implications and Directions for Research}

This study is the first to empirically test students' adoption of SMS as a potential learning tool in higher education. The results indicate that more college students would like to use SMS for learning - for example, 165 out of 225 students agreed or strongly agreed that they would use texting to communicate with others for learning. In addition, as theorized in the TAM literature, both technology characteristics - usefulness and ease of use - positively affect students' intention to adopt SMS for learning. Thus, we empirically confirmed the relationships among three constructs of the TAM - usefulness, ease of use, and intention to adopt - in the context of the SMS adoption for learning.

In addition, the results show that two technology characteristics have different contribution to the SMS adoption. According to the path coefficients of two technology characteristics, usefulness contributes to the user adoption of SMS for learning more than ease of use, where the former assesses the task-oriented technology characteristics and the latter intrinsic technology characteristics. This implies that the two technology characteristics play different roles in the technology adoption, and for the SMS adoption, the task-oriented aspect of technology characteristics plays a more important role. Unlike our findings, Liu, Li, and Carlsson [2] found that ease of use did not influence the mlearning adoption, and concluded that technological restrictions might not induce significant usability problems inhibiting $\mathrm{m}$-learning adoption. While the m-learning tools in their study were tailored specifically for m-learning, i.e., dedicated m-learning tools, SMS is not tailored for m-learning. Thus, depending on mobile devices, the two technology characteristics may have different effects on their adoption.

Since gender difference was discussed as an important socio-cultural factor that affects human perception and behavior [39], its direct effects on the perception and adoption of technology have been tested in the literature [24]. In addition, gender has been identified as one of the four key moderating variables along with experience, age, and voluntariness in the TAM literature [25]. This study is the first to examine the gender difference as a moderating factor in the SMS adoption, and suggests that female students value the ease of use more highly than their counterpart in adopting SMS for learning. In this study, the effect of usefulness on intention to adopt was significant overall, but was not significantly different between male and female students. On the other hand, the effect of ease of use on intention to adopt was significantly stronger for female students than for male students. Our results 


\section{Issues in Information Systems}

Volume 14, Issue 1, pp.10-20, 2013

contrast with those of Ong and Lai [40] who found a significant moderation effect of gender on the path between usefulness and intention to adopt e-learning system, but not on the path between ease of use and intention to adopt elearning system. We can speculate that such contrasting results may be due to the different technologies (i.e., SMS for learning versus e-learning system in general). M-learning is still nascent, and students' response to various learning technologies may differ by gender. Thus, our results imply that the gender difference should be considered when a new technology is designed and implemented for learning in higher education.

Since this study tests only two technological characteristics of usefulness and ease of use on the SMS adoption, we see some possible directions for future research. First, there may be some other factors that can lead to the SMS adoption. For example, future research can extend this research by identifying and testing other factors such as years of SMS experience, age, and major.

Second, it would be interesting to replicate this research with a specific use of SMS or a different mobile device for learning. While participants in this study were asked to use SMS to receive and submit short quizzes outside of the classroom, SMS can also be used as a clicker in the classroom or general communications with instructors. Depending on different uses of SMS, the roles and relationships of usefulness, ease of use, and gender in the SMS adoption may vary.

Finally, it may be interesting to explore the SMS adoption for learning with different theories. For example, IS success model [22] and task technology fit model [21] may be another theoretical model to test the SMS adoption for learning. It would help us better understand how and why students decide to adopt SMS for learning.

\section{Implications for Practice}

Our results indicate that both usefulness and ease of use are significant motivators for using SMS for learning, and the influence of usefulness is more significant than that of ease of use. An important implication for practice from these results is that students are willing to use SMS for learning if the use of SMS can benefit their learning. On the flip side, unless students perceive the usefulness of SMS in learning, they may rarely accept it as a learning tool and keep using it only as a social tool. Thus, it is very important for students to perceive the usefulness of SMS for learning. In order to increase such perceived usefulness, educators should clearly define the contents and scope of using SMS for learning at the stage of course design. In terms of the contents, what information will be sent through SMS should be carefully determined. As compared in Table 1, the main weaknesses of SMS are low flexibility and lack of information richness as its messages are limited to 160 characters. Therefore, various ways of delivering the valuable learning information within 160 characters should be developed. In addition, the scope of SMS message should be clearly defined-e.g., delivering learning materials, sending administrative messages or/and increasing the feeling of connectedness or belongingness in class.

Another implication for practice is that students' perception of ease of use may heighten both perceived usefulness and adoption of SMS for learning. Thus, in order to encourage students to adopt SMS for learning, educators should be able to address issues on ease of use of SMS for learning - whether the contents delivered are easy to read, whether the contents can be retrieved easily for later review, what kind of response is expected in the SMS communication, and so on.

An additional analysis of gender difference on the SMS adoption gives us some interesting implication for practice. We aggregated the four measurement items of intention to adopt the SMS, and found that the mean values of the aggregated variable (i.e., intention to adopt the SMS for learning) are 3.435 for male and 3.818 for female. The $95 \%$ confidence interval for the mean difference between female and male student groups is $(0.07642,0.68870)$, which implies that female college students are more likely to adopt the SMS for learning. Educators can consider the use of SMS for learning more positively when a class has more female students in its student population since they are more likely to adopt the SMS for learning.

Another analysis of gender as a moderator in our model (Table 5) shows that female students perceive the ease of use more importantly in the SMS adoption for learning than male students. This implies that educators may need to consider different aspects of the technology in the SMS adoption for learning depending on gender difference.

\section{REFERENCES}

1. Adkins, S.S., The US market for mobile learning products and services: 2009-2014 forecast and analysis. 2010 , Ambient Insight, LLC.

2. Liu, Y., H. Li, and C. Carlsson, Factors driving the adoption of m-learning: An empirical study. Computers \& Education, 2010. 55(3): p. 1211-1219. 


\section{Issues in Information Systems}

Volume 14, Issue 1, pp.10-20, 2013

3. Cooper, L., Anatomy of an online course. THE Journal (Technological Horizons In Education), 1999. 26(7): p. 49-50.

4. Shim, J.P. and C. Guo, Weblog technology for instruction, learning, and information delivery. Decision Sciences Journal of Innovative Education, 2009. 7(1): p. 171-193.

5. Maurer, H., Web-based knowledge management. Computer, 1998. 31(3): p. 122-123.

6. Holzinger, A., A. Nischelwitzer, and M. Meisenberger. Mobile phones as a challenge for m-learning: Examples for mobile interactive learning objects (MILOs). in Third IEEE International Conference on Pervasive Computing and Communications Workshops. 2005.

7. Virvou, M. and E. Alepis, Mobile educational features in authoring tools for personalised tutoring. Computers \& Education, 2005. 44(1): p. 53-68.

8. Gay, G., et al., The effects of wireless computing in collaborative learning environments. International Journal of Human-Computer Interaction, 2001. 13(2): p. 257-276.

9. Goldman, P. and B. Kaufman, How to push an elephant through a straw: Using wireless technology in a webenhanced skills program. International Review of Law Computers and Technology, 2001. 15(3): p. $281-299$.

10. Anderson, T.M., What you need to know about smart phones 2.0, in Kiplinger's Personal Finance. 2009. p. 79.

11. Purcell, K., R. Entner, and N. Henderson, The rise of apps culture. 2010, Pew Research Center.

12. The Nielsen Company. How teens use media. 2009 [cited; Available from: http://blog.nielsen.com/nielsenwire/reports/nielsen_howteensusemedia_june09.pdf.

13. Naismith, L., Using text messaging to support administrative communication in higher education. Active Learning in Higher Education, 2007. 8(2): p. 155.

14. Cavus, N. and D. Ibrahim, M-learning: An experiment in using SMS to support learning new English language words. British Journal of Educational Technology, 2009. 40(1): p. 78-91.

15. Rau, P.L.P., Q. Gao, and L.M. Wu, Using mobile communication technology in high school education: Motivation, pressure, and learning performance. Computers \& Education, 2008. 50(1): p. 1-22.

16. Stone, A., J. Briggs, and C. Smith. SMS and interactivity - Some results from the field, and its implications on effective uses of mobile technologies in education. in IEEE International Workshop on Wireless and Mobile Technologies in Education. 2002: IEEE Computer Society.

17. Garner, I., J. Francis, and K. Wales, An evaluation of the implementation of a short messaging system (SMS) to support undergraduate students, in Proceedings of the European Workshop on Mobile and Contextual Learning. 2002: Birmingham, UK. p. 15-18.

18. Wang, M., et al., The impact of mobile learning on students' learning behaviours and performance: Report from a large blended classroom. British Journal of Educational Technology, 2009. 40(4): p. 673-695.

19. Zagorsky, J.L., E-mail, computer usage and college students: A case study. Education, 1997. 118(1).

20. Bures, E., P. Abrami, and C. Amundsen, Student motivation to learn via computer conferencing. Research in Higher Education, 2000. 41(5): p. 593-621.

21. Goodhue, D.L., Understanding user evaluations of information systems. Management Science, 1995. 41(12): p. 1827-1844.

22. DeLone, W.H. and E.R. McLean, Information systems success: The quest for the dependent variable. Information Systems Research, 1992. 3(1): p. 60-95.

23. Davis, F.D., Perceived usefulness, perceived ease of use, and user acceptance of information technology. MIS Quarterly, 1989. 13(3): p. 319-340.

24. Gefen, D. and D. Straub, Gender difference in the perception and use of e-mail: An extension to the technology acceptance model. MIS Quarterly, 1997. 21(4): p. 389-400.

25. Venkatesh, V., et al., User acceptance of information technology: Toward a unified view. MIS Quarterly, 2003. 27(3): p. 425-478.

26. Minton, H.L. and F.W. Schneider, Differential psychology. 1980, Prospect Heights, IL: Waveland Press.

27. Venkatesh, V. and M.G. Morris, Why don't men ever stop to ask for directions? Gender, social influence, and their role in technology acceptance and usage behavior. MIS Quarterly, 2000. 24(1): p. 115-139.

28. Ringle, C.M., S. Wende, and S. Will, SmartPLS 2.0 (M3) Beta. 2005, http://www.smartpls.de: Hamburg.

29. Marcoulides, G.A. and C. Saunders, PLS: A silver bullet? MIS Quarterly, 2006. 30(2): p. iii-ix.

30. Tobias, R.D. An introduction to partial least squares regression. in SAS Users Group International (SUGI) Annual Conference. 1995. Orlando, FL.

31. Fornell, C. and F.L. Bookstein, Two structural equation models: LISREL and PLS applied to consumer exitvoice theory. Journal of Marketing Research, 1982. 19(4): p. 440-452. 


\section{Issues in Information Systems}

Volume 14, Issue 1, pp.10-20, 2013

32. Bearden, W.O., R.G. Netemeyer, and M.F. Mobley, Handbook of marketing scales. 1993, Newbury Park, CA: Sage.

33. Yi, M.Y. and F.D. Davis, Developing and validating an observational learning model of computer software training and skill acquisition. Information Systems Research, 2003. 14(2): p. 146-169.

34. Hair, J.F., et al., Multivariate data analysis. Fifth ed. 1998, Upper Saddle River, New Jersey, U.S.A.: Prentice Hall.

35. Nunnally, J.C., Psychometric theory. 1967, New York: McGraw-Hill.

36. Chin, W.W., The partial least squares approach to structural equation modeling, in Modern Methods for Business Research, G.A. Marcoulides, Editor. 1998, Lawrence Erlbaum Associates: Mahwah, NJ. p. 295-336.

37. Fornell, C. and D.F. Larcker, Evaluating structural equation models with unobservable variables and measurement error. Journal of Marketing Research, 1981. 18(1): p. 39-50.

38. Keil, M., et al., A cross-cultural study on escalation of commitment behavior in software projects. MIS Quarterly, 2000. 24(2): p. 299-325.

39. Hofstede, G., Culture's consequences: International differences in work related values. 1980, London: SAGE.

40. Ong, C.-S. and J.-Y. Lai, Gender differences in perceptions and relationships among dominants of e-learning acceptance. Computers in Human Behavior, 2006. 22(5): p. 816-829. 